\title{
Cost Implications and Complications of Overtreatment of Low-Risk Prostate Cancer in the United States
}

\author{
Ayal A. Aizer, MD, MHS'; Xiangmei Gu, MS ; Ming-Hui Chen, $\mathrm{PhD}^{\mathrm{c}}$; Toni K. Choueiri, MD; \\ Neil E. Martin, MD, MPH'; Jason A. Efstathiou, MD, DPhilf; Andrew S. Hyatt, BA ${ }^{\mathrm{e}}$;

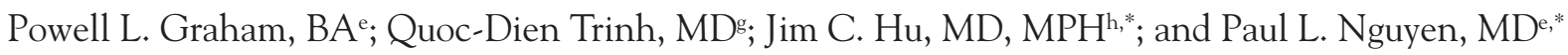

\begin{abstract}
Background: Evidence-based consensus guidelines recommend only observation for men with low-risk prostate cancer and life expectancy less than 10 years. This report describes the incidence, drivers, cost, and morbidity of overtreatment of low-risk prostate cancer within the United States. Methods: The SEER-Medicare Program was used to identify 11,744 men aged 66 years or older diagnosed with low-risk prostate cancer in 2004 through 2007. Overtreatment of prostate cancer was defined as definitive treatment of a patient with a life expectancy of less than 10 years. Expected survival was estimated using NCCN methodology. Costs were the amount paid by Medicare in years after minus year before diagnosis. Toxicities were relevant Medicare diagnoses/interventions. $P$ values are 2-sided. Results: Of 3001 men with low-risk prostate cancer and a life expectancy of less than 10 years, 2011 men (67\%) were overtreated. On multivariable logistic regression, overtreated men were more likely to be married (odds ratio [OR], $1.29 ; 95 \% \mathrm{Cl}, 1.05-1.59 ; P=.02)$, reside in affluent regions $(P<.001)$, and harbor more advanced disease at diagnosis $(P<.001)$. Two-year toxicity was greater in overtreated patients $(P<.001)$. Relative to active surveillance/watchful waiting/observation, the median additional cost per definitive treatment was $\$ 18,827$ over 5 years; the cumulative annual cost attributable to overtreatment in the United States was $\$ 58.7$ million. The ability to avoid treating the $80 \%$ of men with lowgrade disease who will never die of prostate cancer would save $\$ 1.32$ billion per year nationally. Conclusions: Overtreatment of low-risk prostate cancer is partially driven by sociodemographic factors and occurs frequently, with marked impact on patient quality of life and health-related costs. (J Natl Compr Canc Netw 2015;13:61-68)
\end{abstract}

\section{Background}

As the most common malignancy affecting American men, ${ }^{1}$ prostate cancer has a substantial economic impact, and the cost of its management is projected to increase at a rate greater than that of any other cancer. $^{2}$ Prostate cancer is often overtreated in the United States, as the 10-year disease-specific mortality rate for appropriately selected patients managed with active surveillance approaches $0 \%,{ }^{3-5}$ and a recently published

\footnotetext{
From a Harvard Radiation Oncology Program, Boston, Massachusetts; ${ }^{\text {b} C e n t e r ~ f o r ~ S u r g e r y ~ \& ~ P u b l i c ~ H e a l t h, ~ B r i g h a m ~ a n d ~ W o m e n ' s ~ H o s p i t a l, ~}$ Boston, Massachusetts; 'Department of Statistics, University of Connecticut, Storrs, Connecticut; ${ }^{\mathrm{d}}$ Dana-Farber Cancer Institute, Brigham and Women's Hospital, Boston, Massachusetts; eDepartment of Radiation Oncology, Brigham and Women's Hospital/Dana-Farber Cancer Institute, Boston, Massachusetts; 'Department of Radiation Oncology, Massachusetts General Hospital, Boston, Massachusetts; ' $D$ Department of Urology, Brigham and Women's Hospital, Boston, Massachusetts; and hDepartment of Urology, University of California, Los Angeles, Los Angeles, California.

"Authors contributed equally to this work.

Submitted January 21, 2014; accepted for publication March 5, 2014.
}

randomized clinical trial showed no survival benefit to prostatectomy versus observation in patients with lowrisk disease. $^{6}$

In recommending against prostate-specific antigen (PSA) screening for prostate cancer, the US Preventative Services Task Force (USPSTF) described overtreatment of indolent disease as a major source of unnecessary harm from screening. ${ }^{7}$ In addition, the NCCN Clinical Practice Guidelines in Oncology (NCCN Guidelines)
The authors have disclosed that they have no financial interests, arrangements, affiliations, or commercial interests with the manufacturers of any products discussed in this article or their competitors. This work was supported by a Heritage Medical Research Institute/Prostate Cancer Foundation Young Investigator Award (to PN); Joint Center for Radiation Therapy Foundation Grant (to PN); Fitz's Cancer Warriors (to PN); David and Cynthia Chapin (to PN); and a grant from an anonymous family foundation (to PN).

Correspondence: Paul L. Nguyen, MD, Brigham and Women's Hospital, Department of Radiation Oncology, 75 Francis Street, Boston, MA 02115. E-mail: pnguyen@Iroc.harvard.edu 
for Prostate Cancer $^{8}$ recommend active surveillance as an appropriate option for all men with low-risk prostate cancer (Gleason score $\leq 6$, pretreatment PSA level $<10 \mathrm{ng} / \mathrm{mL}$, and clinical stage T1-T2a), a group that accounts for $35 \%$ to $70 \%$ of all patients with prostate cancer, ${ }^{9,10}$ and state that observation is the only appropriate option for men with low-risk prostate cancer and a life expectancy of less than 10 years.

The purpose of this study was to define, on a large scale, the incidence, risk factors, economic burden, and morbidity related to overly aggressive treatment of patients with low-risk prostate cancer and a short life expectancy in the United States.

\section{Subjects/Patients and Methods}

\section{Patient Characteristics and Study Design}

A population-based study was conducted of patients with low-risk prostate cancer identified by the SEERMedicare Program ${ }^{11}$ who were diagnosed between 2004 to 2007 and who were 66 years of age or older. Sponsored by the NCI, SEER captures approximately $97 \%$ of incident cancers and encompasses $26 \%$ to $28 \%$ of the US population. SEER data have been linked to Medicare claims with a very high success rate. ${ }^{12}$ Patients were considered low risk if they possessed a clinical stage T2a or lower, Gleason score of 6 or lower, and PSA level less than $10 \mathrm{ng} / \mathrm{mL}$, as defined by NCCN. ${ }^{8}$ From the original cohort of 139,370 men with prostate cancer, patients were excluded if they were diagnosed at autopsy $(n=3626)$, lacked pathologic confirmation $(n=2760)$, were receiving Medicare benefits because of end-stage renal disease/disability $(\mathrm{n}=8827)$, had discrepancies in the date of death between SEER and Medicare $(n=875)$, were younger than 66 years at diagnosis $(n=30,438)$, had incomplete staging information or cancer that was more advanced than low-risk $(n=73,720)$, were not enrolled in Medicare Part A or Part B or were enrolled in a managed care plan from 12 months before diagnosis to 12 months after diagnosis $(n=7273)$, or had an unclear treatment plan $(n=107)$, leaving 11,744 men in the final cohort. Patients who underwent radical prostatectomy, external-beam radiation therapy, brachytherapy, or cryotherapy within 12 months of diagnosis were considered to have undergone definitive treatment. Definitive treatment of a patient with a life expectancy less than 10 years con- stituted overtreatment, as specified by the NCCN Guidelines for Prostate Cancer. ${ }^{8}$ Notably, primary androgen deprivation therapy was defined as use of hormonal therapy in the absence of definitive therapy, such as external-beam radiation, brachytherapy, or prostatectomy.

\section{Determination of Expected Survival}

Expected survival was estimated using data from the 2007 Social Security Life Table, updated in 2012. ${ }^{13}$ The expected survival of patients in the upper and lower quartiles of comorbidity was increased and decreased by $50 \%$, respectively, an approach stipulated by $\mathrm{NCCN}^{8}$ and validated by population-level data. ${ }^{14}$ Comorbidity was determined using the Elixhauser Index, ${ }^{15}$ as updated by Quan et al. ${ }^{16}$

\section{Cost and Toxicity Analysis}

Cost was determined by calculating the cumulative amount paid by Medicare for inpatient, outpatient, and physician services after a diagnosis of prostate cancer. Each patient was used as their own control and the cumulative medical cost incurred during the 12 months before the diagnosis was subtracted from the cumulative medical cost each year after the diagnosis for a total of 5 years, an approach which allowed the capture of costs related to both therapy and complications of therapy, in consensus with several previous reports. ${ }^{17}$ Men undergoing primary androgen deprivation therapy were excluded from the cost analysis. All reported costs were adjusted to 2010 dollars using the 2007 Annual Report of the Boards of Trustees of the Federal Hospital Insurance and Federal Supplementary Medical Insurance Trust Fund Table 5.B.1 HI and SMI Average Per Beneficiary Costs (HI Part A; SMI Part B). ${ }^{17}$ Cost was only calculated in patients for whom Medicare was the primary insurer for the entirety of the follow-up period.

Thirty-day postoperative complications were recorded in patients undergoing prostatectomy. Longterm genitourinary and gastrointestinal complications (defined as those occurring within 2 years of initiation of management) were recorded. Interventions were identified using either Current Procedural Terminology (CPT) codes or diagnosis codes from the International Classification of Diseases, ninth revision (ICD-9).

\section{Statistical Analysis}

Continuous and categorical baseline characteristics for patients with a life expectancy of 10 years or more 
versus less than 10 years were compared using the Wilcoxon rank sum test and Chi-square test, respectively. Multivariable logistic regression was performed to determine factors associated with use of definitive therapy in patients with a life expectancy of less than 10 years. Long-term adverse effects in patients undergoing radical prostatectomy or radiation therapy were compared with active surveillance/watchful waiting/ observation using the Fisher exact test. All $P$ values are 2-sided, and a threshold of .05 was used to determine significance. Statistical analyses were performed using SAS v9.3 (SAS Institute, Cary, NC). This study was approved by the Dana-Farber/Harvard Cancer Center Institutional Review Board, and a waiver for informed consent was obtained.

\section{Results}

\section{Patient Characteristics}

Baseline patient characteristics in patients with an expected survival of 10 years or more versus less than 10 years are presented in Table 1 . Patients with a life expectancy of less than 10 years were older and had greater comorbidity than those with a life expectancy of 10 years or more. Other baseline differences were either small in magnitude or nonsignificant.

\section{Factors Associated With Overtreatment}

Among the 3001 patients with a life expectancy of less than 10 years, 2011 (67\%) underwent definitive treatment within 12 months of diagnosis. Notably, of patients with an expected survival of 10 years or more, $72 \%$ underwent definitive treatment within 12 months of diagnosis. On multivariable logistic regression analysis of men with a life expectancy of less than 10 years (Table 2 ), patients who were overtreated were more likely to be married (odds ratio [OR], 1.29; 95\% CI, 1.05-1.59; $P=.02$ ), reside in affluent regions, and harbor more advanced disease at diagnosis $(P<.001)$.

\section{Cost Analysis}

At 5 years, the cumulative crude median cost per patient who was overtreated was $\$ 26,937$, whereas the cumulative cost for patients who underwent active surveillance/watchful waiting/observation (including the cost of definitive therapy after year one in patients for whom active surveillance/watchful waiting/observation was discontinued) was $\$ 8110$, for a net median difference of $\$ 18,827$ per patient (Figure $1)$. Newer, radiation-based therapies were the most costly (Table 3). Because SEER captures $26 \%$ of the US population, and assuming that the $38 \%$ of patients who either were enrolled in Medicare Advantage, had another primary payer, or were not enrolled

\begin{tabular}{|c|c|c|c|}
\hline Characteristic & $\begin{array}{l}\text { Expected Survival } \geq 10 y^{a} \\
(\mathrm{~N}=8743)\end{array}$ & $\begin{array}{l}\text { Expected Survival }<10 y^{a} \\
(\mathrm{~N}=3001)\end{array}$ & $P$ Value \\
\hline Age at diagnosis, N (\%) & & & $<.001$ \\
\hline $66-69$ y & 3269 (37) & $621(21)$ & \\
\hline $70-74 y$ & 3447 (39) & $728(24)$ & \\
\hline$\geq 75 y$ & $2027(23)$ & $1652(55)$ & \\
\hline Comorbidities (Elixhauser), N (\%) & & & $<.001$ \\
\hline 0 & $4374(50.0)$ & $99(3.3)$ & \\
\hline 1 & $2611(30.0)$ & $882(29.0)$ & \\
\hline$\geq 2$ & $1758(20.0)$ & $2020(67.0)$ & \\
\hline Race, N (\%) & & & 11 \\
\hline White & $6971(80.0)$ & $2372(79.0)$ & \\
\hline Black & $758(8.7)$ & $246(8.2)$ & \\
\hline Hispanic & $505(5.8)$ & $171(5.7)$ & \\
\hline Asian & $284(3.2)$ & $127(4.2)$ & \\
\hline Other & $225(2.6)$ & $85(2.8)$ & \\
\hline Clinical stage, N (\%) & & & .09 \\
\hline T1 & $7847(90)$ & $2660(89)$ & \\
\hline $\mathrm{T} 2$ & $896(10)$ & $341(11)$ & \\
\hline PSA, ng/mL, median (IQR) & $5.5(4.4-7.0)$ & $5.6(4.5-7.3)$ & .10 \\
\hline Treatment, N (\%) & & & $<.001$ \\
\hline AS/WW/O & $2418(28.0)$ & $990(33.0)$ & \\
\hline Prostatectomy & $1333(15.0)$ & $238(7.9)$ & \\
\hline Radiation & $4992(57.0)$ & $1773(59.0)$ & \\
\hline
\end{tabular}

Abbreviations: AS, active surveillance; IQR, interquartile range; O, observation; PSA, prostate-specific antigen; WW, watchful waiting. aPercentages may not add up to $100 \%$ because of rounding.

*An expanded version of this table is available online, in this article, at JNCCN.org. 
Aizer et al

\begin{tabular}{|c|c|c|c|c|}
\hline Variable & $\begin{array}{l}\text { Univariable OR } \\
(95 \% \mathrm{Cl})\end{array}$ & $P$ Value & $\begin{array}{l}\text { Multivariable OR } \\
(95 \% \mathrm{Cl})\end{array}$ & $P$ Value \\
\hline $\begin{array}{l}\text { Race } \\
\text { White } \\
\text { Black } \\
\text { Hispanic } \\
\text { Asian }\end{array}$ & $\begin{array}{l}\text { Ref } \\
1.01(0.75-1.36) \\
1.25(0.84-1.80) \\
1.04(0.70-1.55)\end{array}$ & $\begin{array}{l}- \\
.96 \\
.24 \\
.84\end{array}$ & $\begin{array}{l}\text { Ref } \\
0.92(0.65-1.29) \\
1.43(0.93-2.22) \\
1.05(0.65-1.71)\end{array}$ & $\begin{array}{l}- \\
.62 \\
.11 \\
.84\end{array}$ \\
\hline $\begin{array}{l}\text { Marital status } \\
\text { Unmarried } \\
\text { Married }\end{array}$ & $\begin{array}{l}\text { Ref } \\
1.38(1.14-1.68)\end{array}$ & .001 & $\begin{array}{l}\text { Ref } \\
1.29(1.05-1.59)\end{array}$ & -.02 \\
\hline $\begin{array}{l}\text { High school education }^{b} \\
<75 \% \\
75.00 \%-84.99 \% \\
85.00 \%-89.99 \% \\
\geq 90 \%\end{array}$ & $\begin{array}{l}\text { Ref } \\
1.12(0.87-1.43) \\
1.06(0.82-1.38) \\
0.95(0.76-1.18)\end{array}$ & $\begin{array}{l}- \\
.39 \\
.64 \\
.95\end{array}$ & $\begin{array}{l}\text { Ref } \\
1.08(0.81-1.44) \\
0.93(0.67-1.29) \\
0.70(0.50-0.99)\end{array}$ & $\begin{array}{l}- \\
.59 \\
.65 \\
.04\end{array}$ \\
\hline $\begin{array}{l}\text { Median annual household in } \\
<\$ 35,000 \\
\$ 35,000-\$ 44,999 \\
\$ 45,000-\$ 59,999 \\
\geq \$ 60,000\end{array}$ & $\begin{array}{l}\text { Ref } \\
1.06(0.86-1.32) \\
1.27(1.02-1.59) \\
1.21(0.96-1.53)\end{array}$ & $\begin{array}{l}- \\
.58 \\
.03 \\
.11\end{array}$ & $\begin{array}{l}\text { Ref } \\
1.20(0.92-1.55) \\
1.61(1.19-2.18) \\
1.87(1.31-2.68)\end{array}$ & $\begin{array}{l}- \\
.17 \\
.002 \\
<.001\end{array}$ \\
\hline $\begin{array}{l}\text { Clinical stage } \\
\text { T1 } \\
\text { T2 }\end{array}$ & $\begin{array}{l}\text { Ref } \\
1.41(1.07-1.84)\end{array}$ & .01 & $\begin{array}{l}\text { Ref } \\
1.62(1.22-2.15)\end{array}$ & $\begin{array}{l}- \\
<.001\end{array}$ \\
\hline PSA (per $1 \mathrm{ng} / \mathrm{mL}$ increase) & $1.02(1.01-1.02)$ & $<.001$ & $1.02(1.02-1.02)$ & $<.001$ \\
\hline
\end{tabular}

Abbreviations: OR, odds ratio; PSA, prostate-specific antigen; Ref, reference.

avertreatment defined as definitive treatment of a low-risk patient with a life expectancy $<10$ years within 12 months of diagnosis.

${ }^{\text {b} A s ~ d e t e r m i n e d ~ b y ~} 2000$ US Census Tract; missing data for 1 patient.

*An expanded version of this table is available online, in this article, at JNCCN.org.

in Part A or Part B incurred similar costs and active surveillance/watchful waiting/observation rates as patients in the Medicare-based fee-for-service reimbursement schemes incorporated into the cost analysis, the cumulative cost of unnecessary treatment of prostate cancer in men 66 years of age or older in the United States can be estimated to be $\$ 58.7$ million/ annum. Because approximately $80 \%$ of men with prostate cancer and a Gleason score of 6 or less will not die of their disease, ${ }^{18}$ and given that 87,728 cases of localized prostate cancer and a Gleason score of 6 or less were diagnosed in the United States in 2009 (per SEER ${ }^{11}$ data after accounting for upgrading ${ }^{19-22}$ at prostatectomy), better identification of men unlikely to die of prostate cancer (and avoidance of upfront definitive therapy in these men) could allow for a savings of $\$ 1.32$ billion/annum.

\section{Morbidity}

Thirty-day complications after prostatectomy and long-term complications after prostatectomy, radiation, and active surveillance/watchful waiting/observation are presented in Table 4. Patients undergoing either prostatectomy or radiation experienced significantly higher rates of long-term toxicity than those managed with active surveillance/watchful waiting/ observation $(P<.001)$. Urinary, erectile, and bowel toxicity within 2 years occurred in 59\% and 50\%, $48 \%$ and $20 \%$, and $7.1 \%$ and $18.0 \%$ of patients who underwent prostatectomy and radiation, respectively.

\section{Discussion}

In this study of patients with low-risk prostate cancer, the authors found that a high percentage $(67 \%)$ of men with a life expectancy of less than 10 years undergo upfront definitive treatment. Interestingly, this percentage was only $5 \%$ lower than the $72 \%$ rate of definitive treatment in patients with a life expectancy of 10 years or more.

Prospective series of low-risk patients managed with active surveillance report 10 -year prostate cancer-specific survival rates of nearly $100 \% .^{3-5} \mathrm{Ad}$ ditionally, the PIVOT trial showed that the 12-year prostate cancer-specific survival rates with observation and radical prostatectomy were both $97.7 \% .^{6}$ 
Therefore, NCCN considers definitive surgical or radio-therapeutic treatment of low-risk patients with a life expectancy of less than 10 years to be overtreatment; these results suggest that significant overtreatment of prostate cancer exists in the United States.

It is important to recognize that transrectal, ultrasound-guided prostate biopsies can undergrade ${ }^{19,23}$ and understage ${ }^{24}$ patients with prostate cancer. Unlike those with low-risk disease, patients with intermediate-risk and high-risk cancer have a significant risk of death from prostate cancer within 10 years of diagnosis. ${ }^{25,26}$ Because of this risk, a significant percentage of patients eligible for active surveillance decide not to pursue it. ${ }^{27}$ Therefore, obtaining at least 12 cores during biopsy and considering the use of prostate MRI are important to attempt to better exclude the presence of more advanced or aggressive disease in patients with apparent low-risk prostate cancer. ${ }^{28,29}$ This may be particularly important in African American patients, who are at increased risk of undergrading/understaging. ${ }^{24}$ More recently, molecular/genomic testing has preliminarily shown significant promise in predicting the aggressiveness of prostate cancer beyond what can be achieved based on the typical prognostic factors. ${ }^{30-32}$ Although this testing holds significant promise for identifying more appropriate candidates for active surveillance, further validation is required before molecular/genomic testing can be routinely used in clinical practice.

Implications of these results are substantial. Definitive treatment of patients with prostate cancer is known to be associated with significant genitourinary

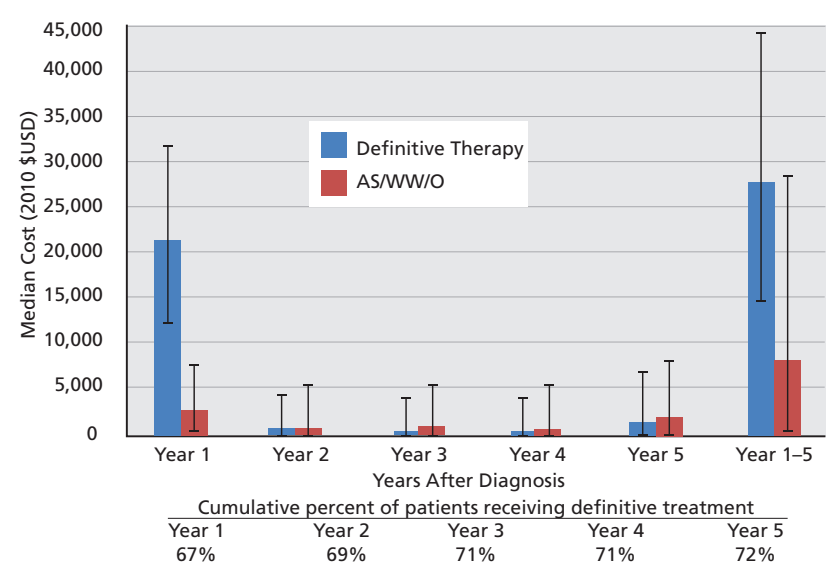

Figure 1 Cost of definitive therapy relative to AS/WW/O at 5 years in men with a life expectancy $<10$ years. Cumulative percentages of definitive therapy (reflecting crossover from active surveillance to surgery or radiation) are presented at the bottom of the figure. Vertical black lines represent the interquartile range. Each annual dollar amount was discounted to time zero.

Abbreviations: AS, active surveillance; O, observation; WW, watchful waiting.

and gastrointestinal toxicity, ${ }^{33}$ and active surveillance is believed to be associated with improved quality of life compared with definitive therapy. ${ }^{9}$ These data suggest that overtreatment of men exposes them to unnecessary toxicity, as evidenced by the high rates of short-and long-term toxicity seen in this study.

The cost associated with the management of prostate cancer in the United States is substantial and likely reflects the rapid adoption of newer, more expensive therapies, such as minimally invasive radical prostatectomy and intensity-modulated radiation therapy. ${ }^{17}$ One recent study suggested

\section{Table 3 Adjusted Median Cost ${ }^{2}$ of Each Management Modality for Prostate Cancer}

\begin{tabular}{|c|c|c|c|}
\hline Management Modality & $\mathbf{N}$ & Cost $^{b}$ & IQR \\
\hline Radical retropubic/perineal prostatectomy & 143 & 13,868 & $10,629-21,203$ \\
\hline Minimally invasive radical prostatectomy & 88 & 14,157 & $9849-20,188$ \\
\hline Brachytherapy & 937 & 16,883 & $11,482-28,105$ \\
\hline External-beam radiation therapy & 145 & 18,592 & $13,105-24,713$ \\
\hline Image-guided radiation therapy/stereotactic radiation therapy & 116 & 26,930 & $22,263-36,260$ \\
\hline Intensity-modulated radiation therapy & 445 & 29,616 & $23,664-40,271$ \\
\hline Proton therapy & 21 & 42,772 & $35,214-53,176$ \\
\hline Cryotherapy & 64 & 12,516 & $9816-16,517$ \\
\hline AS/WW/O & 760 & 2766 & $518-7806$ \\
\hline Primary androgen deprivation therapy & 195 & 7070 & $3231-13,409$ \\
\hline
\end{tabular}

Abbreviations: AS, active surveillance; IQR, interquartile range; O, observation; WW, watchful waiting.

${ }^{a}$ Costs were the amount paid by Medicare in the year after minus the year before diagnosis in patients with a life expectancy $<10$ years.

${ }^{\mathrm{b}}$ As measured per patient in 2010 \$USD. 
that, even among men with low-risk prostate cancer or a limited life expectancy, the use of these more expensive technologies is increasing. ${ }^{34}$ Active surveillance/observation allows for avoidance of expensive therapeutic modalities in at least $40 \%$ to $60 \%$ of patients at 10 years, $3,4,35$ and this percentage seems to be much higher in the present study's population of men with a short life expectancy. Results of this study showed that improved adherence to NCCN Guidelines in avoiding treatment of low-risk disease in men whose life expectancy is less than 10 years would save $\$ 58$ million annually. Furthermore, no perfect test currently exists to distinguish the $20 \%$ of patients with low-grade (Gleason score $\leq 6$ ) prostate cancer who will succumb to their untreated disease versus the $80 \%$ whose disease will not be fatal despite lack of treatment (molecular/ genomic testing holds promise in this regard), but if such a test existed and could spare the $80 \%$ from treatment, the annual savings would be $\$ 1.32$ billion, an amount greater than $25 \%$ of the entire NCI's annual budget for 2012. ${ }^{36}$

Nationally, only $5 \%$ to $9 \%$ of patients with low-risk prostate cancer undergo active surveillance/watchful waiting/observation; the remainder are treated definitively. ${ }^{37}$ The underlying reason for overtreatment of prostate cancer is unknown but is likely related to the poor ability of physicians to assess life expectancy, ${ }^{38-40}$ overestimation of the benefit of definitive therapy, ${ }^{41}$ and the presence of physician bias. ${ }^{41-43}$ Interventions to avoid overtreatment of prostate cancer should entail provisions to improve physician awareness of life expectancy, national guidelines, and the potential harms caused by overtreatment in elderly men with significant comorbidity. Higher physician reimbursement associated with

\begin{tabular}{|c|c|c|c|c|c|}
\hline Complication & $\begin{array}{l}\text { AS/WW/O } \\
(\mathrm{N}=990)\end{array}$ & $\begin{array}{l}\text { Radical } \\
\text { Prostatectomy } \\
(\mathrm{N}=238)\end{array}$ & P Value $^{a}$ & $\begin{array}{l}\text { Radiation } \\
\text { Therapy } \\
(\mathrm{N}=1773)\end{array}$ & $P$ Value $^{\text {b }}$ \\
\hline Heterologous blood transfusion, N (\%) & - & $30(13)$ & & - & \\
\hline $\begin{array}{l}\text { 30-d postoperative complications, N (\%) } \\
\text { Overall } \\
\text { Cardiopulmonary } \\
\text { Genitourinary/wound } \\
\text { Vascular } \\
\text { Miscellaneous medical } \\
\text { Miscellaneous surgical }\end{array}$ & $\begin{array}{l}- \\
- \\
- \\
- \\
- \\
-\end{array}$ & $\begin{array}{l}53(22.0) \\
18(7.6) \\
12(5.0) \\
16(6.7) \\
19(7.9) \\
13(5.5)\end{array}$ & & $\begin{array}{l}- \\
- \\
- \\
- \\
- \\
-\end{array}$ & \\
\hline Stricture, N (\%) & $50(5.1)$ & $25(11.0)$ & .004 & $102(6.0)$ & .49 \\
\hline $\begin{array}{l}\text { Long-term toxicity, any, N (\%) } \\
\text { Diagnosis } \\
\text { Procedure } \\
\text { Either/both }\end{array}$ & $\begin{array}{l}430(43) \\
273(28) \\
513(52)\end{array}$ & $\begin{array}{r}185(78) \\
87(37) \\
189(79)\end{array}$ & $\begin{array}{r}<.001 \\
.007 \\
<.001\end{array}$ & $\begin{array}{r}1029(58) \\
691(39) \\
1160(65)\end{array}$ & $\begin{array}{l}<.001 \\
<.001 \\
<.001\end{array}$ \\
\hline $\begin{array}{l}\text { Long-term toxicity, urinary, N (\%) } \\
\text { Diagnosis } \\
\text { Procedure } \\
\text { Either/bothc }\end{array}$ & $\begin{array}{l}286(29) \\
273(28) \\
403(41)\end{array}$ & $\begin{array}{r}129(54) \\
80(34) \\
141(59)\end{array}$ & $\begin{array}{l}<.001 \\
.07 \\
<.001\end{array}$ & $\begin{array}{l}686(39) \\
685(39) \\
887(50)\end{array}$ & $\begin{array}{l}<.001 \\
<.001 \\
<.001\end{array}$ \\
\hline $\begin{array}{l}\text { Long-term toxicity, bowel, N (\%) } \\
\text { Diagnosis } \\
\text { Either/both }\end{array}$ & $\begin{array}{l}106(11) \\
106(11)\end{array}$ & $\begin{array}{l}17(7.1) \\
17(7.1)\end{array}$ & $\begin{array}{l}.12 \\
.12\end{array}$ & $\begin{array}{l}314(18) \\
316(18)\end{array}$ & $\begin{array}{l}<.001 \\
<.001\end{array}$ \\
\hline $\begin{array}{l}\text { Long-term toxicity, erectile, } \mathrm{N}(\%)^{\mathrm{d}} \\
\text { Diagnosis } \\
\text { Either/both }\end{array}$ & $\begin{array}{l}130(13) \\
130(13)\end{array}$ & $\begin{array}{l}113(47) \\
114(48)\end{array}$ & $\begin{array}{l}<.001 \\
<.001\end{array}$ & $\begin{array}{l}349(20) \\
349(20)\end{array}$ & $\begin{array}{l}<.001 \\
<.001\end{array}$ \\
\hline
\end{tabular}

Abbreviations: AS, active surveillance; O, observation; WW, watchful waiting.

a $P$ value reflects comparison of radical prostatectomy to AS/WW/O.

bP value reflects comparison of radiation therapy to $A S / W W / O$.

'Refers to either a diagnosis or a procedure, or both.

dSuppressed data related to patients undergoing procedures for this toxicity to avoid cells with $<11$ patients, as recommended by SEER-Medicare Program. 
definitive therapy as opposed to active surveillance/ observation may incentivize overtreatment. ${ }^{44}$ In a landmark study, Mitchell and Sunshine ${ }^{45}$ showed that the practice pattern of non-radiation oncologists referring patients for radiation therapy at centers in which they have ownership is associated with an approximate $46 \%$ increase in costs relative to nonconflicted practices. Of concern, estimates show that approximately $20 \%$ of radiation oncology centers are owned by referring physicians, resulting in the overuse of expensive management modalities. ${ }^{46}$ Restructuring of payment models and further limitations on self-referral specified by the Stark Law may combat the incentivizing of definitive therapy. ${ }^{47}$

The USPSTF recently recommended against PSA-based screening for prostate cancer because of the risks of overdiagnosis and overtreatment. ${ }^{7}$ Although the European Randomized Screening Trial for Prostate Cancer showed a $20 \%$ relative reduction in prostate cancer mortality with screening, the USPSTF believed that the ratio of 1055 needed to screen to 37 needed to treat to prevent 1 death at 11 years was too high a price. ${ }^{48}$ However, rather than eliminating screening altogether, another strategy is to continue screening but limit treatment only to those who need it.

Certain limitations of the present study warrant discussion. Because complete managed care claims data are largely not available, the cohort only comprised patients in fee-for-service programs. ${ }^{49}$ Second, because SEER generally reports the highest Gleason score obtained at either biopsy or prostatectomy, patients upgraded at prostatectomy may not have been captured, thereby resulting in artificially low estimates of overtreatment. Third, although patients undergoing primary androgen deprivation therapy were not included because this study focused on definitive local therapy, primary androgen deprivation therapy can be considered one of the most severe forms of overtreatment in low-risk patients, because it is not curative as a monotherapy and has a significant side effect profile. Lastly, the cost estimates used in this study were based on Medicare reimbursement rates; patients younger than 66 years, who were not captured in this study, may have private insurance, which often reimburses at higher rates than Medicare, thus underestimating the cost estimates reported in this study.

Despite these limitations, this study indicates that overtreatment of men with low-risk prostate cancer and limited life expectancy is very common in the United States, and seems to be driven partially by sociodemographic factors. The impact of overtreatment on quality of life and health care cost is substantial. Efforts toward patient and physician education and improvements in care delivery models are likely needed to reduce overtreatment, which is one of the major sources of harm from PSA screening.

\section{Acknowledgments}

This study used the linked SEER-Medicare database. The interpretation and reporting of these data are the sole responsibility of the authors. The authors acknowledge the efforts of the Applied Research Program, NCI; the Office of Research, Development and Information, CMS; Information Management Services (IMS), Inc.; and the SEER program tumor registries in the creation of the SEER-Medicare database.

\section{References}

1. Siegel R, Naishadham D, Jemal A. Cancer statistics, 2012. CA Cancer J Clin 2012;62:10-29.

2. Mariotto $A B$, Yabroff $K R$, Shao Y, et al. Projections of the cost of cancer care in the United States: 2010-2020. J Natl Cancer Inst 2011;103:117128.

3. van den Bergh RC, Roemeling S, Roobol MJ, et al. Outcomes of men with screen-detected prostate cancer eligible for active surveillance who were managed expectantly. Eur Urol 2009;55:1-8

4. Tosoian JJ, Trock BJ, Landis $P$, et al. Active surveillance program for prostate cancer: an update of the Johns Hopkins experience. J Clin Oncol 2011;29:2185-2190.

5. Dall'Era MA, Konety BR, Cowan JE, et al. Active surveillance for the management of prostate cancer in a contemporary cohort. Cancer 2008;112:2664-2670.

6. Wilt TJ, Brawer MK, Jones KM, et al. Radical prostatectomy versus observation for localized prostate cancer. N Engl J Med 2012;367:203-213.

7. Moyer VA. Screening for prostate cancer: U.S. Preventive Services Task Force recommendation statement. Ann Intern Med 2012;157:120-134.

8. Mohler JL, Armstrong AJ, Bahnson RR, et al. NCCN Clinical Practice Guidelines in Oncology: Prostate Cancer. Version 1, 2015. Available at: NCCN.org. Accessed April 4, 2014

9. Hayes JH, Ollendorf DA, Pearson SD, et al. Active surveillance compared with initial treatment for men with low-risk prostate cancer: a decision analysis. JAMA 2010;304:2373-2380

10. Shao $\mathrm{YH}$, Demissie $\mathrm{K}$, Shih $\mathrm{W}$, et al. Contemporary risk profile of prostate cancer in the United States. J Natl Cancer Inst 2009;101:1280-1283.

11. Surveillance, Epidemiology, and End Results (SEER) Program (www. seer.cancer.gov) Research Data (1973-2009), National Cancer Institute, DCCPS, Surveillance Research Program, Surveillance Systems Branch, released April 2012, based on the November 2011 submission. Available at: http://appliedresearch.cancer.gov/seermedicare/obtain/requests.html.

12. Warren JL, Klabunde CN, Schrag D, et al. Overview of the SEERMedicare data: content, research applications, and generalizability to the United States elderly population. Med Care 2002;40(8 Suppl):IV-3-18.

13. Actuarial Life Table, Year 2007. Social Security Administration. Available at: http://www.ssa.gov/OACT/STATS/table4c6.html. Accessed September 19, 2012.

14. Walter LC, Covinsky KE. Cancer screening in elderly patients: a framework for individualized decision making. JAMA 2001;285:2750-2756. 


\section{Aizer et al}

15. Elixhauser A, Steiner C, Harris DR, Coffey RM. Comorbidity measures for use with administrative data. Med Care 1998;36:8-27.

16. Quan H, Sundararajan V, Halfon P, et al. Coding algorithms for defining comorbidities in ICD-9-CM and ICD-10 administrative data. Med Care 2005;43:1130-1139.

17. Nguyen PL, Gu X, Lipsitz SR, et al. Cost implications of the rapid adoption of newer technologies for treating prostate cancer. J Clin Oncol 2011;29:1517-1524.

18. Albertsen PC, Hanley JA, Fine J. 20-year outcomes following conservative management of clinically localized prostate cancer. JAMA 2005;293:20952101.

19. King CR, McNeal JE, Gill H, Presti JC Jr. Extended prostate biopsy scheme improves reliability of Gleason grading: implications for radiotherapy patients. Int J Radiat Oncol Biol Phys 2004;59:386-391.

20. San Francisco IF, DeWolf WC, Rosen S, et al. Extended prostate needle biopsy improves concordance of Gleason grading between prostate needle biopsy and radical prostatectomy. J Urol 2003;169:136-140.

21. Divrik RT, Eroglu A, Sahin A, et al. Increasing the number of biopsies increases the concordance of Gleason scores of needle biopsies and prostatectomy specimens. Urol Oncol 2007;25:376-382.

22. Emiliozzi P, Maymone S, Paterno A, et al. Increased accuracy of biopsy Gleason score obtained by extended needle biopsy. J Urol 2004;172(6 Pt 1):2224-2226

23. Moussa AS, Kattan MW, Berglund R, et al. A nomogram for predicting upgrading in patients with low- and intermediate-grade prostate cancer in the era of extended prostate sampling. BJU Int 2010;105:352-358.

24. Sundi D, Ross AE, Humphreys EB, et al. African American men with very low-risk prostate cancer exhibit adverse oncologic outcomes after radical prostatectomy: should active surveillance still be an option for them? J Clin Oncol 2013;31:2991-2997.

25. D'Amico AV, Manola J, Loffredo M, et al. 6-month androgen suppression plus radiation therapy vs radiation therapy alone for patients with clinically localized prostate cancer: a randomized controlled trial. JAMA 2004;292:821-827.

26. Bolla M, Gonzalez D, Warde P, et al. Improved survival in patients with locally advanced prostate cancer treated with radiotherapy and goserelin. N Engl J Med 1997;337:295-300.

27. Cooperberg MR, Carroll PR, Klotz L. Active surveillance for prostate cancer: progress and promise. J Clin Oncol 2011;29:3669-3676.

28. Uno H, Nakano M, Ehara H, Deguchi T. Indications for extended 14-core transrectal ultrasound-guided prostate biopsy. Urology 2008;71:23-27.

29. Bittencourt LK, Barentsz JO, de Miranda LC, Gasparetto EL. Prostate MRI: diffusion-weighted imaging at $1.5 \mathrm{~T}$ correlates better with prostatectomy Gleason grades than TRUS-guided biopsies in peripheral zone tumours. Eur Radiol 2012;22:468-475.

30. Freedland SJ, Gerber L, Reid J, et al. Prognostic utility of cell cycle progression score in men with prostate cancer after primary external beam radiation therapy. Int J Radiat Oncol Biol Phys 2013;86:848-853.

31. Cuzick J, Swanson GP, Fisher G, et al. Prognostic value of an RNA expression signature derived from cell cycle proliferation genes in patients with prostate cancer: a retrospective study. Lancet Oncol 2011;12:245255.

32. Knezevic D, Goddard AD, Natraj N, et al. Analytical validation of the Oncotype DX prostate cancer assay-a clinical RT-PCR assay optimized for prostate needle biopsies. BMC Genomics 2013;14:690.
33. Sanda MG, Dunn RL, Michalski J, et al. Quality of life and satisfaction with outcome among prostate-cancer survivors. N Engl J Med 2008;358:1250 1261.

34. Jacobs BL, Zhang Y, Schroeck FR, et al. Use of advanced treatment technologies among men at low risk of dying from prostate cancer. JAMA 2013;309:2587-2595.

35. Klotz L, Zhang L, Lam A, et al. Clinical results of long-term follow-up of a large, active surveillance cohort with localized prostate cancer. J Clin Oncol 2010;28:126-131.

36. 2012 Budget Request. National Cancer Institute Web site. Available at: http://www.cancer.gov/aboutnci/budget_planning_leg/plan2012/2012budgetrequest. Accessed May 2, 2013.

37. Cooperberg MR, Broering JM, Carroll PR. Time trends and local variation in primary treatment of localized prostate cancer. J Clin Oncol 2010;28:1117-1123.

38. Feliu J, Jimenez-Gordo AM, Madero R, et al. Development and validation of a prognostic nomogram for terminally ill cancer patients. J Natl Cancer Inst 2011;103:1613-1620.

39. Chow E, Davis L, Panzarella T, et al. Accuracy of survival prediction by palliative radiation oncologists. Int J Radiat Oncol Biol Phys 2005;61:870873.

40. Froehner M, Koch R, Litz RJ, et al. Which patients are at the highest risk of dying from competing causes $</=10$ years after radical prostatectomy? BJU Int 2012;110:206-210.

41. Fowler FJ Jr, McNaughton Collins M, Albertsen PC, et al. Comparison of recommendations by urologists and radiation oncologists for treatment of clinically localized prostate cancer. JAMA 2000;283:3217-3222.

42. Aizer AA, Paly JJ, Zietman AL, et al. Multidisciplinary care and pursuit of active surveillance in low-risk prostate cancer. J Clin Oncol 2012;30:30713076.

43. Moore MJ, O'Sullivan B, Tannock IF. How expert physicians would wish to be treated if they had genitourinary cancer. J Clin Oncol 1988;6:17361745.

44. Falit BP, Gross CP, Roberts KB. Integrated prostate cancer centers and over-utilization of IMRT: a close look at fee-for-service medicine in radiation oncology. Int J Radiat Oncol Biol Phys 2010;76:1285-1288.

45. Mitchell JM, Sunshine JH. Consequences of physicians' ownership of health care facilities--joint ventures in radiation therapy. N Engl J Med 1992;327:1497-1501.

46. Anscher MS. Self-referral in radiation oncology: has caveat emptor replaced primum non nocere? Int J Radiat Oncol Biol Phys 2012;84:874.

47. Anscher MS, Anscher BM, Bradley CJ. The negative impact of stark law exemptions on graduate medical education and health care costs: the example of radiation oncology. Int J Radiat Oncol Biol Phys 2010;76:12891294.

48. Schroder FH, Hugosson J, Roobol MJ, et al. Prostate-cancer mortality at 11 years of follow-up. N Engl J Med 2012;366:981-990.

49. Medicare Advantage 2012 Data Spotlight: Enrollment Market Update. The Henry J. Kaiser Family Foundation Web site. Available at: http://www. kff.org/medicare/8323.cfm. Accessed September 23, 2012. 